\title{
Knowledge and attitudes of Latin American obstetricians and gynecologists regarding intrauterine contraceptives
}

This article was published in the following Dove Press journal:

International Journal of Women's Health

16 July 2015

Number of times this article has been viewed

\author{
Luis Bahamondes' \\ Maria Y Makuch' \\ Ilza Monteiro' \\ Victor Marin ${ }^{2}$ \\ Richard Lynen ${ }^{3}$ \\ 'Department of Obstetrics and \\ Gynecology, School of Medical \\ Sciences, University of Campinas, \\ Campinas, Brazil; ${ }^{2}$ Department of \\ Obstetrics and Gynecology, Hospital \\ Central, Petróleos Mexicanos, México \\ City, Mexico; ${ }^{3}$ Bayer HealthCare, \\ Newark, NJ, USA
}

Background: Intrauterine contraceptives (IUCs), including the copper intrauterine device and the levonorgestrel-releasing intrauterine system (LNG-IUS), are among the reversible contraceptive methods with high effectiveness. However, use is low in many settings, including some Latin American countries, mainly due to the influences of myths, fears, and negative attitudes, not only of users and potential users, but also of different cadres of health care professionals. The purpose of this study was to assess the knowledge and attitudes of a group of Latin American obstetricians and gynecologists regarding IUCs.

Methods: A survey was conducted during a scientific meeting organized in Chile in 2014 to present and discuss updated information about contraception. Obstetricians and gynecologists from 12 Latin American countries, who reported that they provide daily contraception services in both the public and private sectors, participated in the meeting. Participants who agreed to take part in the survey responded to a multiple-choice questionnaire on issues regarding knowledge, use, and attitudes about IUCs.

Results: Of the 210 obstetricians and gynecologists participating in the meeting, the respondents to each question varied from $168(80.0 \%)$ to 205 (97.6\%). Almost 50\% recognized that the failure rate of combined oral contraceptives, patches, and vaginal rings is $8 \%-10 \%$. Furthermore, $10 \%$ of the participants did not recognize the high contraceptive effectiveness of long-acting reversible contraceptive methods. Additionally, almost $80 \%$ of the respondents answered that they did not offer IUCs to nulligravidas and almost $10 \%$ did not offer IUCs to adolescents, albeit almost $90 \%$ of the respondents reported that nulligravidas are candidates for an LNG-IUS.

Conclusion: Some deficiencies and contradictions in terms of knowledge and attitudes were identified from the answers of the Latin American obstetricians and gynecologists who participated in the survey. The knowledge and attitudes of health care professionals about IUCs are important in order to provide adequate counseling and to expand the use of IUCs.

Keywords: contraception, Latin America, intrauterine contraceptives, health care professionals, knowledge, myths, attitudes

\section{Introduction}

Intrauterine contraceptives (IUCs) and subdermal contraceptive implants are long-acting reversible contraceptive (LARCs) methods with high effectiveness. ${ }^{1,2}$ The effectiveness of perfect use of these methods is similar to typical use. Due to the high number of unintended pregnancies that occur in developed and developing countries, ${ }^{3}$ the high effectiveness of LARC methods, including IUCs like the TCu380A intrauterine device (IUD) and both the 20 and $12 \mu \mathrm{g} /$ day levonorgestrel-releasing intrauterine systems (LNG-IUSs), have great importance in contraception. IUCs are able to prevent unintended pregnancies with only one procedure of placement and long-term use.
Correspondence: Luis Bahamondes Department of Obstetrics and Gynecology, School of Medical Sciences, University of Campinas, Caixa Postal 6I8I, Campinas |3084-97|,

Sao Paulo, Brazil

Tel +55 I9 32895207

$\mathrm{Fax}+551932892440$

Email bahamond@caism.unicamp.br 
It is estimated that four of ten pregnancies that occur worldwide are unintended, and that one of the highest rates, with six in ten unintended pregnancies, is in Latin America (LA). ${ }^{3,4}$ Unintended pregnancy is a complex issue, and the availability of contraceptive methods is one of the strategies to reduce the high rates. Further, it is important that contraceptive methods are not only available but are also provided at an affordable $\operatorname{cost},{ }^{5}$ that national programs have adequate facilities with hours of attention organized according to the convenience and needs of the women and couples consulting, and that an adequate approach is included for adolescents. It is also important to have trained health care professionals (HCPs) to provide family planning services and adequate counseling. ${ }^{6}$

The unmet need for contraception is still high in both developing and developed countries, and it is more evident among the low-income portion of society, ie, rural communities and adolescents. ${ }^{7}$ Additionally, one of the issues that aggravates the high unmet need for contraception is the difficult access worldwide (particularly in developing settings) to LARC methods, and the existing barriers for potential users. $^{2}$

Beyond the fact that IUCs have one of the highest contraceptive efficacies when compared with methods that require daily or weekly attention like combined oral contraceptives (COCs), vaginal rings, and patches, ${ }^{2,8}$ the great advantages are the scarce contraindications and side effects, and that their use is discrete, an important aspect mainly for adolescents. ${ }^{9}$ The use of all contraceptive methods, and particularly IUCs, is strongly influenced by myths, fears, and negative attitudes, not only of users and potential users but also of different cadres of HCPs. It is mentioned in the scientific literature that common knowledge about risks and side effects of contraceptive methods is higher than knowledge regarding the benefits of these methods. ${ }^{10}$

In many LA countries, obstetricians and gynecologists (OBGYN) are an important source of information about contraception for many women, including adolescents. OBGYN are often the first-line response for HCPs who provide contraception services, including the insertion of IUCs. For this reason, it is important that OBGYN are updated on IUCs, not only by being skilled in the insertion procedure but also trained to provide adequate counseling before placement and during follow-up in order to clarify doubts, improve knowledge of users, reduce premature discontinuation rates, and to improve long-term continuation. Based on these considerations, the objective of this study was to assess the knowledge and attitudes of a group of LA OBGYN regarding the use and prescription of IUCs.

\section{Materials and methods}

The subjects in this study were OBGYN from 12 LA countries who participated in a scientific meeting in Chile, organized by Bayer HealthCare in the second quarter of 2014. The objective of the meeting was to provide updated information on contraceptive methods. All participants in the meeting had experience in providing attention in contraception and all were invited, at the time of registration, to take part in the study by responding to a multiple-choice questionnaire using an interactive audience response system at the end of each lecture. The questions regarding IUCs in this questionnaire were analyzed for this paper. Data regarding COC have already been published. ${ }^{11}$

Prior to participation, an explanation were given on the objectives of the survey to all participants, that participation was voluntary, that anonymity would be maintained by identifying the keypads only with a number, and that by answering the questions, the OBGYN were giving their consent to participate in the study. The study protocol and the procedure used to obtain consent were approved by the ethics committee at the University of Campinas, Brazil.

The questionnaire, designed especially for this survey, contained questions regarding the demographics (nationality, age, sex, training, clinical experience in family planning, and location of work [public, private, or both]) of the participants. Also, information on attitudes, practice, and knowledge regarding IUCs, including contraceptive performance and eligibility criteria for using this type of contraceptive. The questions were multiple-choice and organized for the participants to provide feedback on the lectures attended during the meeting. For each theme discussed during the meeting, five multiple-choice questions, each with five possible answers were developed. The questions were developed by the researchers and discussed via e-mail with a group of LA OBGYN with recognized expertise in the area of contraception who did not participate in the meeting.

The OBGYN who consented to participate in the study received electronic keypads to answer the questions, which were projected on the screen after each lecture. The questions had to be completed after each lecture in approximately 3 minutes; after that time, the system automatically locked and no new information could be introduced. During the meeting, one of the authors supervised the information provided in the survey and the distribution and collection of the electronic devices to guarantee the accuracy of the procedure.

For this paper, all questions related to the characteristics of the participants, and the knowledge, use, and 
prescribing of IUCs were selected. For the data analysis, a simple descriptive analysis was performed on the dependent variable to examine the knowledge, use, and prescription of IUCs. Afterward, the dependent variables were analyzed taking into account age ( $\leq 49$ years or $\geq 50$ years), sex (male/female), and the sector in which the OBGYN worked (exclusively public, or both private and public). The statistical analysis was performed using the Pearson's $\chi^{2}$, Yates' $\chi^{2}$, and Fisher's exact tests. The software used was Statistical Package for the Social Sciences version 20.0 (IBM Corporation, Armonk, NY, USA). Statistical significance was established at $P<0.05$.

\section{Results}

In total, 210 OBGYN participated in the meeting, and the number of respondents to each question varied from 168 (80.0\%) to 205 (97.6\%). The mean ( \pm standard deviation) age of the participants was $48.7 \pm 10.6$ (range $30-72$ ) years. Eighty-eight (41.9\%) were female and 122 (58.1\%) were male. Practicing only in the public sector was reported by five $(2.4 \%)$ OBGYN, practicing only in the private sector was reported by 81 (38.6\%), and practicing in both the public and private sectors was reported by $112(55.3 \%)$.

Table 1 shows the answers given by the participants regarding the failure rate of IUCs and comparison of these rates with COCs. Most participants (75\%-86\%) responded that almost $50 \%$ of users of the $\mathrm{COC}$, patch, and vaginal ring continued use of these contraceptives after 1 year. Additionally, almost $50 \%$ answered that the failure rate of the COC, patch, and vaginal ring is $8 \%-10 \%$. However, most of the participants $(90 \%)$ responded that the failure rate of LARC methods is 0.3 per 100 women-years.

Table 2 shows the myths and attitudes of the participating OBGYN regarding use and placement of IUCs. Almost $80 \%$ of respondents answered that they did not offer an IUC to nulligravidas and almost $10 \%$ did not offer an IUC to adolescents. When we evaluated barriers to placement of an IUC, $72.5 \%-82.5 \%$ of the responding OBGYN reported that they did not utilize nonsteroidal anti-inflammatory drugs before insertion, that IUC could be fitted at any time of the menstrual cycle, that ultrasound was not mandatory before placement, and that pain during the procedure was not worse among nulligravidas. In addition, almost $90 \%$ of the respondents answered that the LNG-IUS could be inserted in a nulligravida.

\section{Discussion}

Our results show some of the myths and barriers persisting among the LA OBGYN who participated in this meeting, even after specific lectures regarding different aspects of the IUC. Almost $50 \%$ believed that the effectiveness of the COC, patch, or vaginal ring was higher than the reported rates. ${ }^{12}$ Further, almost $10 \%$ reported contraceptive failure rates of LARC methods that were higher than that reported in the scientific literature. ${ }^{12}$ These misconceptions were more common among older OBGYN and those who worked only in the public sector.

LARCs, including IUCs, are among the methods with the highest contraceptive effectiveness. ${ }^{1,2}$ Considering the

Table I Answers provided by obstetricians and gynecologists regarding failure rate of different contraceptive methods

\begin{tabular}{|c|c|c|c|c|c|c|}
\hline & \multicolumn{6}{|c|}{ OBGYN characteristics } \\
\hline & \multicolumn{2}{|l|}{ Age (\%) } & \multicolumn{2}{|l|}{$\operatorname{Sex}(\%)$} & \multicolumn{2}{|l|}{ Working (\%) } \\
\hline & $\leq 49$ years & $\geq 50$ years & Female & Male & Public sector & Private/public sector \\
\hline \multirow{3}{*}{\multicolumn{7}{|c|}{$\begin{array}{l}\text { What proportion of women use } \\
\text { shorter acting methods (COC, patch, } \\
\text { vaginal ring) up to I year? }(n=\mid 68) \text { : }\end{array}$}} \\
\hline & & & & & & \\
\hline & & & & & & \\
\hline $50 \%-55 \%$ & 79.0 & 82.1 & 86.8 & 75.6 & 78.8 & 82.0 \\
\hline $80 \%-85 \%$ & 21.0 & 17.9 & 13.2 & 24.4 & 21.2 & 18.0 \\
\hline \multirow{2}{*}{\multicolumn{7}{|c|}{$\begin{array}{l}\text { Failure rate of } C O C \text {, patch, and vaginal } \\
\text { ring given typical use }(n=I 75) \text { : }\end{array}$}} \\
\hline & & & & & & \\
\hline $1 \%-2 \%$ & 32.5 & 34.4 & 38.0 & 30.0 & 32.7 & 34.5 \\
\hline $4 \%$ & 16.2 & 24.1 & II.I & 27.1 & 17.3 & 21.0 \\
\hline $8 \%$ & 31.1 & 29.3 & 28.6 & 31.4 & 32.7 & 28.4 \\
\hline $10 \%$ & 20.3 & 12.1 & 22.2 & $\mathrm{I} \mid .4$ & 17.3 & 16.0 \\
\hline \multicolumn{7}{|c|}{ Failure rate per 100 women/year of } \\
\hline \multicolumn{7}{|c|}{ LARC methods up to I year $(n=194)$ : } \\
\hline 0.3 & 95.6 & 80.8 & 88.9 & 88.8 & 83.3 & 90.3 \\
\hline 5.0 & 0.0 & 5.8 & 0.0 & 5.7 & 2.8 & 3.2 \\
\hline 13.0 & 4.4 & 9.6 & I I.I & 3.8 & I I.I & 4.8 \\
\hline 22.0 & 0.0 & 3.8 & 0.0 & 3.8 & 2.8 & 1.7 \\
\hline
\end{tabular}

Abbreviations: COC, combined oral contraceptive; LARC, long-acting reversible contraceptive. 
Table 2 Answers provided by obstetricians and gynecologists regarding some aspects of use of intrauterine contraceptives

\begin{tabular}{|c|c|c|c|c|c|c|}
\hline & \multicolumn{2}{|l|}{ Age (\%) } & \multicolumn{2}{|l|}{$\operatorname{Sex}(\%)$} & \multicolumn{2}{|l|}{ Working (\%) } \\
\hline & $\leq 49$ years & $\geq \mathbf{5 0}$ years & Female & Male & Public sector & Private/public sector \\
\hline \multicolumn{7}{|l|}{ Do you offer IUC regularly } \\
\hline \multicolumn{7}{|l|}{ to your patients? $(\mathrm{n}=202)$ : } \\
\hline Never & 7.1 & 8.9 & 10.6 & 5.5 & 10.5 & 6.2 \\
\hline Not to adolescents & 8.9 & 8.9 & 10.6 & 7.3 & 5.3 & 10.9 \\
\hline Not to nulligravidas & 80.3 & 82.2 & 74.5 & 87.2 & 81.6 & 81.3 \\
\hline Ever & 3.6 & 0.0 & 4.3 & 0.0 & 2.6 & 1.6 \\
\hline \multicolumn{7}{|l|}{ Main barriers between } \\
\hline \multicolumn{7}{|l|}{$\begin{array}{l}\text { OBGYN and patients to IUC } \\
\text { use }(n=205) \text { : }\end{array}$} \\
\hline $\begin{array}{l}\text { NSAIDs are mandatory before } \\
\text { insertion for pain control }\end{array}$ & 10.1 & 9.5 & 7.3 & 11.4 & 10.9 & 8.9 \\
\hline $\begin{array}{l}\text { Could be inserted at any time } \\
\text { within the menstrual cycle }\end{array}$ & 2.9 & 4.8 & 3.6 & 3.8 & 1.8 & 5.1 \\
\hline $\begin{array}{l}\text { TVUS is mandatory before } \\
\text { insertion }\end{array}$ & 8.7 & 1.6 & 7.3 & 3.8 & 9.1 & 2.5 \\
\hline $\begin{array}{l}\text { Pain is more intense } \\
\text { in nulligravidas }\end{array}$ & 5.8 & 1.6 & 5.5 & 2.5 & 0.0 & 6.3 \\
\hline None of the preceding answers & 72.5 & 82.5 & 76.4 & 78.5 & 78.2 & 77.2 \\
\hline \multicolumn{7}{|l|}{$\begin{array}{l}\text { LNG-IUS must be inserted } \\
\text { in nulligravidas }(n=203 \text { ): }\end{array}$} \\
\hline Never & 0.0 & 1.7 & 0.0 & 1.4 & 0.0 & 1.3 \\
\hline $\begin{array}{l}\text { Only if other contraceptive } \\
\text { is not available }\end{array}$ & 7.0 & 5.0 & 5.0 & 6.8 & 3.6 & 7.6 \\
\hline Ever & 92.9 & 90.0 & 93.4 & 90.5 & 96.3 & 88.6 \\
\hline $\begin{array}{l}\text { Could be inserted, but the } \\
\text { woman must be advised that } \\
\text { effectiveness is low }\end{array}$ & 0.0 & 3.3 & 1.7 & 1.4 & 0.0 & 1.3 \\
\hline $\begin{array}{l}\text { Ovarian cysts in LNG-IUS } \\
\text { users must be treated } \\
\text { with ( } n=205) \text { : }\end{array}$ & & & & & & \\
\hline $\mathrm{COC}$ & 2.7 & 5.0 & 3.3 & 4.0 & 3.3 & 4.1 \\
\hline $\begin{array}{l}\text { Surgery if it does not } \\
\text { disappear in } 2 \text { months }\end{array}$ & 2.7 & 0.0 & 0.0 & 2.7 & 1.6 & 1.4 \\
\hline Removal of LNG-IUS & 1.4 & 0.0 & 1.7 & 0.0 & 0.0 & 1.4 \\
\hline Spontaneously disappeared & 93.2 & 95.0 & 95.0 & 93.3 & 95.1 & 93.2 \\
\hline
\end{tabular}

Abbreviations: COC, combined oral contraceptive; OBGYN, obstetricians and gynecologists; IUC, intrauterine contraceptive; NSAIDs, nonsteroidal anti-inflammatory drugs; TVUS, transvaginal ultrasound; LNG-IUS, levonorgestrel-releasing intrauterine system.

significant proportion of OBGYN in this study who did not recognize this fact, we can speculate that this situation is common among LA OBGYN and this could be a reason why use of IUCs is extremely low in countries like Bolivia, Brazil, and Guatemala. ${ }^{10,13}$ It was described that the effectiveness is one of the main factors reported by women when choosing a contraceptive method.

Further, unintended pregnancy is linked to the effectiveness of the chosen contraceptive; in other words, the use of LARC methods (higher effectiveness) is superior to methods requiring daily or periodic attention (lower effectiveness). ${ }^{1,2,14}$ LARC methods have higher continuation rates than other reversible contraceptive methods ${ }^{2}$ and could help to reduce unintended pregnancy rates. ${ }^{15,16-21}$ LARCs, particularly
IUCs, are the most cost-effective reversible contraceptives because they can be used in the long term with high effectiveness. ${ }^{12,22,23}$

There was a contradictory message in the answers of the OBGYN who participated in this study. Most reported that they did not offer IUCs to nulligravidas, and a small proportion reported that they did not offer this method routinely to adolescents. However, in contrast, the majority of the OBGYN in the study reported that they had ever placed LNG-IUS in nulligravidas. It is reasonable to speculate that when the OBGYN reported that they did not offer copper IUDs to nulligravidas, they were influenced by the misconception that IUD use is linked with the risk of pelvic inflammatory disease (PID). In some settings, 
many HCPs still believe that the copper IUD should not be used in nulligravidas and adolescents because it could increase the risk of PID and may potentially cause tubal infertility. ${ }^{24}$

There is strong evidence that the risk of PID is associated with high-risk sexual behavior and consequently with increased risk of acquisition of a sexually transmitted infection. Further, the risk is not confined by age or parity. Consequently, there are many recommendations from international and national organizations that adolescents and nulligravidas are eligible for IUC placement ${ }^{25-27}$ and it is important to disseminate the information to HCP that the PID is not related to IUC use.

The fact that the participating OBGYN reported restricted use of the IUC in nulligravidas, while at the same time reporting that they offered LNG-IUS to nulligravidas is contradictory. This could be a consequence of the LNGIUS offering, besides high contraceptive efficacy, the added benefit of reducing heavy menstrual bleeding at acceptable cost for selected patients, thus providing a valid alternative to hysterectomy and its potential complications. ${ }^{18,28-30}$ Further, it is reasonable to speculate that the contradictory answers regarding copper IUD and LNG-IUS placement could be related to the pharmaceutical company host. However, information about the copper IUD and the LNG-IUS was provided by different and independent speakers. Also, we need to take into account that the organizing company also manufactures the Nova-T ${ }^{\circledR}$ copper IUD.

It is important to overcome the barriers and dispel myths about highly effective contraceptive methods, including the IUCs. Among the barriers for IUC use, it is possible to count the cost, availability, and poor knowledge about the selection of appropriate candidates for use. Updating the knowledge of OBGYN could have a potential value in removing the myths and misconceptions, and could be one of the main strategies to expand the use of these types of contraceptives. It is important to rethink the strategies used to train and update OBGYN regarding use of LARCs, including IUCs.

Some of the myths and barriers regarding placement of IUCs by OBGYN in adolescents and/or nulligravidas could be due to the paucity of information about IUC use in these groups of women, and for this reason many OBGYN may be hesitant to offer IUCs in this population. OBGYN must be aware about the effectiveness and side effects of IUCs, and that they can be used in adolescents and nulligravidas. It has been reported that users of IUCs are less likely to continue this form of contraception in the long term due to pain and bleeding disturbances. ${ }^{31}$ However, it is important that OBGYN take into account the recent scientific literature ${ }^{2,31}$ showing that IUC use in adolescents and nulliparous women is associated with both high contraceptive effectiveness and low complication rates.

One of the limitations of this study was that we did not obtain information regarding the academic profile of the participants, including their publications in recent years or their academic activity, it is speculated that the profile of the participating OBGYN was more geared to clinical practice than to academia. Another limitation is that we did not evaluate the attendees' satisfaction with the speakers and lectures; it should be noted that we did not obtain this information to avoid possible courtesy bias.

In conclusion, our survey identified some deficiencies and contradictions in terms of knowledge and attitudes from the LA OBGYN who participated in the survey. This information is important to be able to formulate strategies for training and updating information for LA OBGYN in order to increase the use of these methods. The knowledge and attitudes of OBGYN with regard to IUCs is important in their everyday practice for them to be able to provide adequate counseling and expand the use of IUCs. This is an area that could be improved by continuing medical education to increase awareness of the current evidence-based guidelines.

\section{Disclosure}

RL and VM were Bayer HealthCare employees and LB is an occasional consultant for Bayer HealthCare. The authors report no other conflicts of interest in this work.

\section{References}

1. Bahamondes L, Bottura BF, Bahamondes MV, et al. Estimated disabilityadjusted life years averted by long-term provision of long acting contraceptive methods in a Brazilian clinic. Hum Reprod. 2014;29(10): 2163-2170.

2. Winner B, Peipert JF, Zhao Q, et al. Effectiveness of long-acting reversible contraception. N Engl J Med. 2012;366(21):1998-2007.

3. Gipson JD, Koenig MA, Hindin MJ. The effects of unintended pregnancy on infant, child, and parental health: a review of the literature. Stud Fam Plann. 2008;39(1):18-38.

4. Sedgh G, Singh S, Hussain R. Intended and unintended pregnancies worldwide in 2012 and recent trends. Stud Fam Plann. 2014;45(3): 301-314

5. Finer LB, Zolna MR. Shifts in intended and unintended pregnancies in the United States, 2001-2008. Am J Public Health. 2014;104 Suppl 1: S43-S48.

6. Modesto W, Bahamondes MV, Bahamondes L. A randomized clinical trial of the effect of intensive versus non-intensive counselling on discontinuation rates due to bleeding disturbances of three long-acting reversible contraceptives. Hum Reprod. 2014;29(7):1393-1399.

7. Hameed W, Azmat SK, Ali M, et al. Women's empowerment and contraceptive use: the role of independent versus couples' decision-making, from a lower middle income country perspective. PLoS One. 2014;9(8):9. 
8. Amaral G, Foster DG, Biggs MA, Jasik CB, Judd S, Brindis CD. Public savings from the prevention of unintended pregnancy: a cost analysis of family planning services in California. Health Serv Res. 2007;42(5):1960-1980.

9. Friedman JO. Factors associated with contraceptive satisfaction in adolescent women using the IUD. J Pediatr Adolesc Gynecol. 2015;28(1): 38-42.

10. Reading BF. Growth in world contraceptive use stalling; 215 million women's needs still unmet. Available from: http://www.earth-policy. org/data_highlights/2012/highlights26. Accessed October 1, 2014.

11. Bahamondes L, Lira-Plasencia J, Martin R, Marin V, Makuch MY. Knowledge and attitudes of Latin American gynecologists regarding unplanned pregnancy and use of combined oral contraceptives. Int J Womens Health. 2015;7:485-491.

12. Trussell J. Update on and correction to the cost-effectiveness of contraceptives in the United States. Contraception. 2012;85(6):611.

13. Population Reference Bureau. 2014 World Population Data Sheet. Available from: http://www.prb.org/pdf14/2014-world-populationdata-sheet_eng.pdf. Accessed January 5, 2015.

14. Ferreira JM, Nunes FR, Modesto W, Gonçalves MP, Bahamondes L. Reasons for Brazilian women to switch from different contraceptives to long-acting reversible contraceptives. Contraception. 2014;89(1): 17-21.

15. Stanwood NL, Bradley KA. Young pregnant women's knowledge of modern intrauterine devices. Obstet Gynecol. 2006;108(6):1417-1422.

16. Whitaker AK, Johnson LM, Harwood B, Chiappetta L, Creinin MD, Gold MA. Adolescent and young adult women's knowledge of and attitudes toward the intrauterine device. Contraception. 2008; 78(3):211-217.

17. Peipert JF, Zhao Q, Allsworth JE, et al. Continuation and satisfaction of reversible contraception. Obstet Gynecol. 2011;117(5):1105-1113.

18. Blumenthal PD, Voedisch A, Gemzell-Danielsson K. Strategies to prevent unintended pregnancy: increasing use of long-acting reversible contraception. Hum Reprod Update. 2011;17(1):121-137.

19. Harper CC, Blum M, de Bocanegra $\mathrm{H}$, et al. Challenges in translating evidence to practice: the provision of intrauterine contraception. Obstet Gynecol. 2008;111(6):1359-1369.

20. Tyler CP, Whiteman MK, Zapata LB, Curtis KM, Hillis SD, Marchbanks PA. Health care provider attitudes and practices related to intrauterine devices for nulliparous women. Obstet Gynecol. 2012; 119(4):762-771.
21. Madden T, Allsworth JE, Hladky KJ, Secura GM, Peipert JF. Intrauterine contraception in Saint Louis: a survey of obstetrician and gynecologists' knowledge and attitudes. Contraception. 2010;81(2):112-116.

22. Bahamondes L, Faundes A, Sobreira-Lima B, et al. TCu 380A IUD: a reversible permanent contraceptive method in women over 35 years of age. Contraception. 2005;72(5):337-341.

23. Wu JP, Pickle S. Extended use of the intrauterine device: a literature review and recommendations for clinical practice. Contraception. 2014; 89(6):495-503.

24. Hubacher D, Lara-Ricalde R, Taylor DJ, Guerra-Infante F, GuzmánRodríguez R. Use of copper intrauterine devices and the risk of tubal infertility among nulligravid women. $N$ Engl J Med. 2001;345(8): 561-567.

25. World Health Organisation, Department of Reproductive Health. Medical eligibility criteria for contraceptive use. 2010. Available from: http://www.who.int/reproductivehealth/publications/family_planning/9789241563888/en/. Accessed May 30, 2015.

26. Committee on Adolescent Health Care Long-Acting Reversible Contraception Working Group, The American College of Obstetricians and Gynecologists. Committee opinion no. 539: adolescents and long-acting reversible contraception: implants and intrauterine devices. Obstet Gynecol. 2012;120(4):983-988.

27. Grimes DA, Schulz KF. Antibiotic prophylaxis for intrauterine contraceptive device insertion. Cochrane Database Syst Rev. 2001;1: CD001327.

28. Bahamondes MV, de Lima Y, Teich V, Bahamondes L, Monteiro I. Resources and procedures in the treatment of heavy menstrual bleeding with the levonorgestrel-releasing intrauterine system (LNG-IUS) or hysterectomy in Brazil. Contraception. 2012;86(3):244-250.

29. Kaunitz AM, Bissonnette F, Monteiro I, Lukkari-Lax E, Muysers C, Jensen JT. Levonorgestrel-releasing intrauterine system or medroxyprogesterone for heavy menstrual bleeding: a randomized controlled trial. Obstet Gynecol. 2010;116(3):625-632.

30. Heliövaara-Peippo S, Hurskainen R, Teperi J, et al. Quality of life and costs of levonorgestrel-releasing intrauterine system or hysterectomy in the treatment of menorrhagia: a 10-year randomized controlled trial. Am J Obstet Gynecol. 2013;209(6):535.e1-535.e14.

31. Aoun J, Dines VA, Stovall DW, Mete M, Nelson CB, GomezLobo V. Effects of age, parity, and device type on complications and discontinuation of intrauterine devices. Obstet Gynecol. 2014;123(3): 585-592.
International Journal of Women's Health

\section{Publish your work in this journal}

The International Journal of Women's Health is an international, peerreviewed open-access journal publishing original research, reports, editorials, reviews and commentaries on all aspects of women's healthcare including gynecology, obstetrics, and breast cancer. The manuscript management system is completely online and includes

\section{Dovepress}

a very quick and fair peer-review system, which is all easy to use Visit http://www.dovepress.com/testimonials.php to read real quotes from published authors. 